
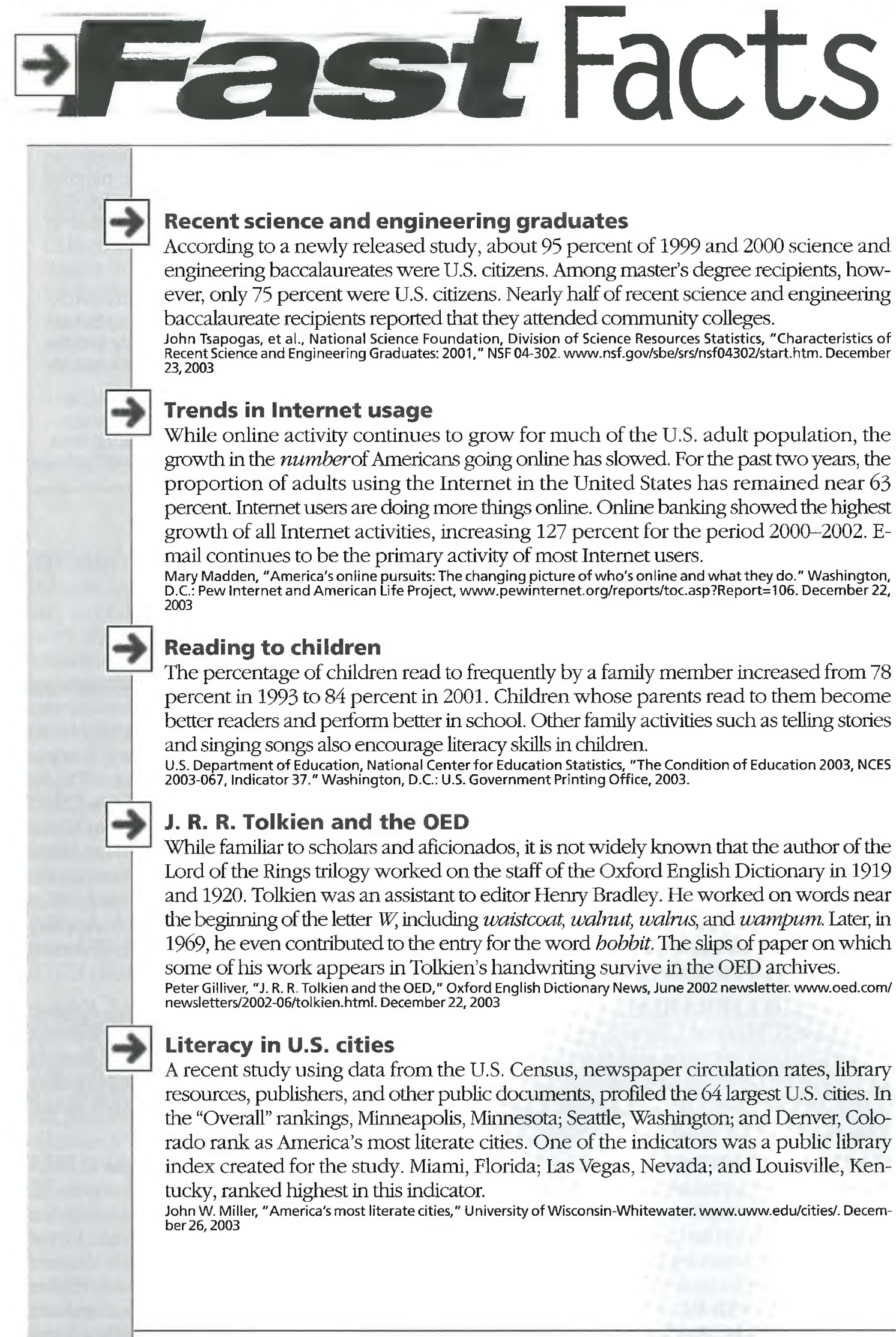

Gary Pattillo is reference librarian at the University of North Carolina-Chapel Hill, e-mail: pattillo@refstaff.lib.unc.edu 


\section{The ACM Digital Library}

\section{The Ultimate Online INFORMATION TECHNOLOGY Resource!}

Discover the ACM Digital Library in the ACM Portal, a vast online resource of ACM's computing and information technology publications. Your patrons can enjoy unlimited access to more than one million pages of full text with archives dating back to the 50 's. This unparalleled resource is a must-have for every technology collection!

The ACM Digital Library includes:

- Over $30 \mathrm{ACM}$ publications, plus conference proceedings

- 48+ years of archives

- Advanced searching capabilities

- 1.2 million pages of downloadable text

Plus, over 750,000 bibliographic citations are available in the $\mathrm{ACM}$ Online Guide

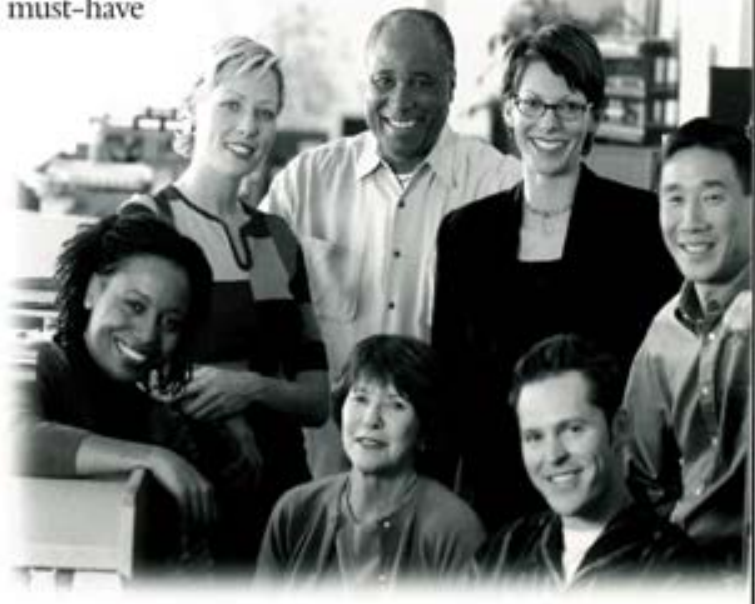

\section{AN EXCEPTIONAL VALUE}

\section{FREE GIFT}

Contact ACM and receive a FREE GIFT * for inquiring about the ACM Digital Library for your institution (while supplies last). Please mention code ADCH24.

*Limited to one per institution/organization

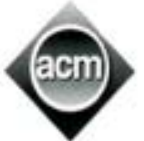

Association for Computing Machinery The First Society in Computing
ACADEMIC INSTITUTIONS, please contact:

ACM Member Services

e-mail: acmhelp@acm.org

phone: +1-212-626-0500

fax: +1-212-944-1318

CORPORATIONS \& CONSORTIA, please contact:

DL Coordinator

e-mail: dl-info@acm.org

phone: +1-212-626-0518

fax: +1-212-944-1318

www.acm.org/dl 


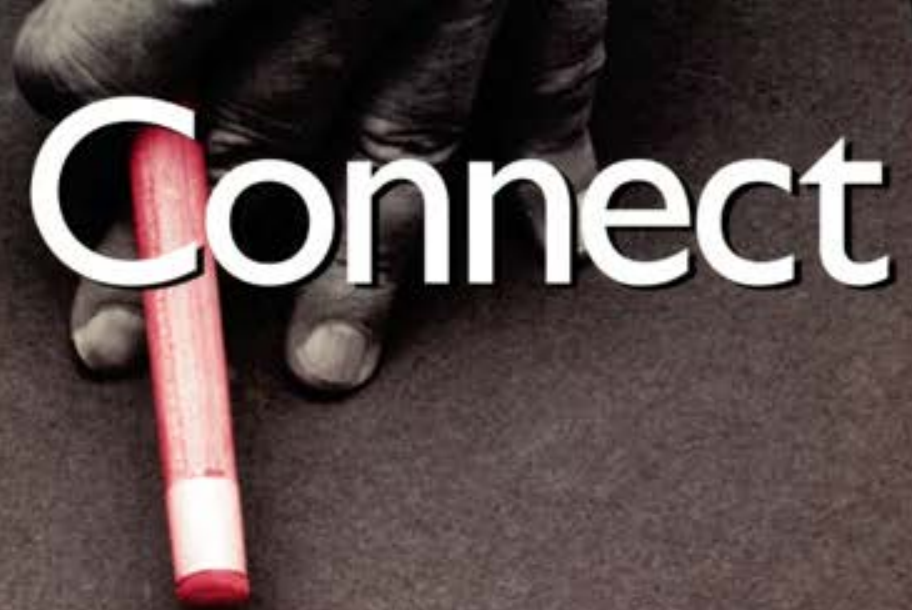

your

patrons

and your staff

with your library's

electronic

resources.

EBSCOhost"

Electronic Journals Service (EJS) has a simplified interface that makes it easy for patrons to find the information they need and a broad suite of administrative tools that saves you valuable time. And with EBSCO's superior linking technology you'll have access to more content from more sources than ever before.

\section{EBSCOhost Electronic} Journals Service. Get connected. 